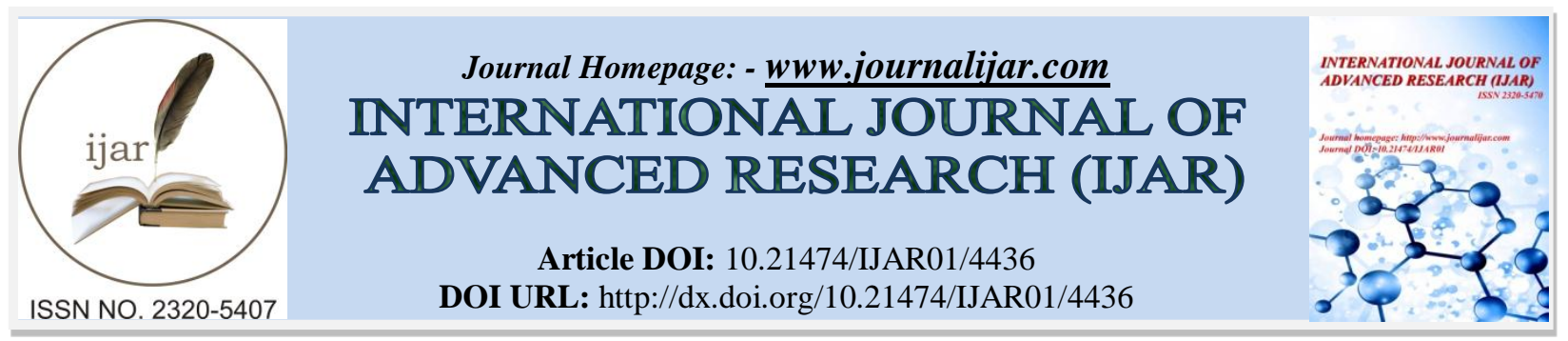

RESEARCH ARTICLE

\title{
EPIDEMIOLOGICAL STUDY OF DIABETES IN THE PROVINCE OF HAUT-OGOOUE (GABON).
}

\section{Ndong Atome Guy Roger ${ }^{1}$, Mickala Patrick ${ }^{2}$, Padzys Guy Stéphane ${ }^{2}$, Ngoua-Meye-Misso Rick-Léonid ${ }^{1}$, Sima Obiang Cédric ${ }^{1}$ and Ouamba Jean Maurille ${ }^{3}$.}

1. Laboratory of Research in Biochemistry (LAREBIO), University of Sciences and Technology of Masuku, P. O. Box 913 Franceville, Gabon.

2. Laboratory of Animal Physiology: Electrophysiology-Pharmacology-URAB, University of Sciences and Technology of Masuku, P. O. Box 913 Franceville, Gabon.

3. Chemistry Unit of the plant and life (UC2V), Faculty of Science and Technology, University Marien Ngouabi (FSTUMNG). P.O.Box 69 Brazzaville, Congo.

\section{Manuscript Info}

\section{Manuscript History}

Received: 10 April 2017

Final Accepted: 12 May 2017

Published: June 2017

Key words:-

Diabetes, Epidemiology, Gabon.

Prevalence, Risk factors.

\section{Abstract}

Background: In the majority of developing countries, noncommunicable diseases such as diabetes and hypertension are booming at the expense of communicable diseases that generally affect poor and middle-income countries. An epidemiological study was carried out in two health institutions: the International Center for Medical Research in Franceville and the Amissa Bongo Hospital Center in Franceville (Haute-Ogooue/ Gabon).

Methods: Were included in the study, patients having a blood glucose $\geq 7 \mathrm{mmol} / \mathrm{L}$ for glucose measurement. Demographic parameters and socio-occupational criteria were recorded for each patient.

Results: The results of this study show a prevalence of diabetics $11.78 \%$. The study also showed that diabetes affects more men than women $\left(\mathrm{p}=2.10^{-7}\right.$, odds ratio $\left.=2.1\right)$. The most exposed age group being 41 to 60 years. Overweight and obesity are risk factors for this disease with respectively $44.10 \%$ and $45.5 \%$ of diabetic patients, thereby increasing the risk of cardiovascular disease The analysis of socioprofessional criteria, showed that the most vulnerable are workers, farmers, housekeepers and unemployed $\left(\mathrm{p}=1.92 .10^{-5}\right.$, odds ratio=2.4).

Conclusions: Ultimately it would be necessary to set up a program to fight against non-communicable diseases and to create an observatory for better supervision of young people and pregnant women for taking health early account of this disease finally create the conditions for struggle against poverty.

Copy Right, IJAR, 2017,. All rights reserved.

\section{Introduction:-}

Contrary to an old conception of diabetes as a disease of rich countries and men, the prevalence of diabetes today is growing exponentially in developing countries and particularly in Africa. The World Health Organization (WHO) reports global growth in the prevalence of 135 million patients in 1995 to 300 million in 2025 [1]. In developing countries, there is a real epidemiological transition from communicable diseases to non-communicable diseases, 
particularly diabetes and hypertension [2]. Although the vast majority of people with diabetes and other noncommunicable diseases (NCDs) live and die in low- and middle-income countries, the prevention and treatment of diabetes and other non-communicable diseases is largely neglected in these countries. One reason may be that, unlike the impacts of acute and transmissible diseases, the pressures on the resources imposed by diabetes are not obvious in appearance [3]. Africa has the highest percentage of undiagnosed diabetes, estimated at 78\% in 2011 [4]. In that same year, 14.7 million adults in the Africa region had diabetes [5]. The prospects for diabetes progression are alarming especially in the developing countries of Africa and Asia; experts do not hesitate to talk about the epidemic situation of diabetes. Age and overweight characterized by increased body mass index (BMI $>25 \mathrm{~kg} / \mathrm{m}^{2}$ ) are in sub-Saharan Africa the main factors of cardiovascular risk associated with diabetes [2]. In Gabon, the known prevalence of diabetes in 2012 was around 6 to $10.19 \%$, making the country one of the three nations most affected by the disease in sub-Saharan Africa [5-6]. However, the association hypertension and diabetes is common in the rest of the world as it concerned $40 \%$ of diabetics at least [7]. The aim of this study is to determine the current prevalence and the associated factors of diabetes from two institutions strongly frequented by patients: the Amissa Bongo Regional Hospital Centers of Franceville and the International Medical Research Center in Franceville.

\section{Materials and Methods:-}

\section{Place and study population:-}

This study was conducted at the observatory of the Research Unit and Medical Analysis (URAM) at the International Medical Research Center in Franceville (CIRMF) and the Regional Hospital Amissa Bongo Franceville in the general medical ward.

\section{Inclusion Criteria:-}

Patients received in consultation at the Research Unit in Medical Analysis (URAM) having a blood glucose demand. In hospital hospitalized and non-hospitalized patients, diagnosed by the physician as new diabetics by measuring capillary glucose twice (blood glucose $\geq 7 \mathrm{mmol} / \mathrm{L}$ ) were included.

\section{Exclusion Criteria:-}

Patients with fasting blood glucose $<7 \mathrm{mmol} / \mathrm{L}$;

\section{Type of study: Retrospective and transversal foresight:- \\ Retrospective study:-}

At URAM, the data collection was carried out by consulting the patient registers on the one hand and consulting the database of the medical analysis manager from November 2012 to June 2014. Cases of Hyperglycemia $\geq 7 \mathrm{mmol} / \mathrm{L}$ on two occasions were considered diabetic.

In the same period, data from diabetic patients were collected from the registries of the Department of General Diabetes Clinic service at the Amissa Bongo Regional Hospital Center considering the inclusion criteria above.

\section{Prospective study:-}

For the prospective study, an informed consent form was established. On this card, the patient gave his approval by signing. Thus, an epidemiological survey questionnaire was established and the patient's information and those concerning his disease were transcribed there. The size and weight of each subject were measured in the morning using a scale and scales, after removing the shoes and any heavy clothing. The body mass index (BMI) was calculated as the weight $(\mathrm{kg}) /$ height $(\mathrm{m})^{2}$ ratio. The questionnaire developed the patient demographics, cardiovascular risk factors and dietary habits. The parameters studied were based on the clinical data of each patient: age, sex, family history of diabetes, and the types of cardiovascular complications observed.

\section{Blood glucose Measurement:-}

At the CIRMF, blood glucose was measured as follows: A volume of 3 to $5 \mathrm{ml}$ of blood was taken from the venous area for blood glucose testing, lipid balance (CT, HDL, LDL and TG) and renal status (creatinine and urea). The blood of the tubes was centrifuged at $3900 \mathrm{rpm}$ for $5 \mathrm{~min}$ and serum analysis was performed by the HITACHI 902 automatic analyzer. The urines were also taken to determine the level of glucose (glycosuria) and the rate of ketones (ketonuria). These assays were performed using a UROTOP ${ }^{+}$Urine Strip. In the hospital setting, diabetes screening was conducted as follows: Capillary blood glucose was measured using a glucose meter. 


\section{The socio-professional categories were Divided into four groups:-}

Category 1: Represented well-to-do social classes, wealthy merchants, senior managers and businessmen;

Category 2: Traders and owners of medium-sized enterprises, master's level managers;

Category 3: Small businesses, small businesses, lower management;

Category 4: Workers, farmers, women in households, unemployed

\section{Ethical Considerations:-}

This study was reviewed and approved by National Committee on Ethics for Research (CNER) of Gabon. Participants were informed that participation is completely voluntary, and written consent was obtained from each participant before being subjected to the questionnaire and after discussing the objective with the participants. No names were recorded on the questionnaires. Adequate training of data collectors took place to ensure protection of confidentiality, and all questionnaires were kept safe.

\section{Statistical Analysis:-}

The data collected was entered on an Excel file (Microsoft Office 2007) and then exported to the software package Epi-Info 6 (version 3.5.1) for statistical analysis. The data were divided into qualitative and quantitative variables; the results of the qualitative (nominal) variables are given in numbers (n) and percentages (\%); as for the quantitative variables, the averages were calculated; the thresholds of statistical significance were considered for $\mathrm{p}$ $<0.05$.

\section{Results:-}

During the study period, from 2012 to 2014, 2104 patients with a blood glucose demand were registered at URAM and Amissa Bongo Regional Hospital Center. Of these 2104, 1078 (51.24\%) were male and 1026 were female, the male-female sex ratio was 1.05 (1078/1026), the mean age was 40 years at age 60] and $41.63 \%$ were between the ages of 21 and 40 years. $75.66 \%$ had a normal BMI.

Of the 2104 patients admitted to the International Center for Medical Research (CIRMF) for screening, 248 had blood glucose levels above $7 \mathrm{mmol} / \mathrm{L}$, giving the overall prevalence of diabetes of $11.78 \%$.

Statistically, diabetes causes more deaths among men than women $\left(\mathrm{p}=2.10^{-7}\right.$, odds ratio $\left.=2.10\right)$. The average age of all diabetics was 40 years [range 15-60 years].

Of the men, 166 are diabetics or $15.39 \%$. Statistically, diabetes causes more deaths among men than women $(\mathrm{p}=$ $2.10^{-7}$, odds ratio $=2.10$ ). The average age of all diabetics was 40 years [range $15-60$ years].

Overweight and obese diabetics accounted for $44.1 \%$ and $45.55 \%$, respectively (Table 1 ).

188 diabetics out of a total of 248 belong to category 4 or $75.80 \%$. The most vulnerable to the disease are workers, farmers, women in the household, and the unemployed $\left(\mathrm{p}=1.92 .10^{-5}\right.$; odds ratio $\left.=2.4\right)$ (Figure 1).

Table 1:- Prevalence of diabetes by different factors

\begin{tabular}{|c|c|c|c|c|c|c|}
\hline \multicolumn{2}{|l|}{ Factors } & $\mathrm{n}=2104$ & $\begin{array}{c}\text { Hyperglycemia } \\
\text { Gluc } \geq 7 \mathrm{mmol} / \mathrm{L}\end{array}$ & Pourcent (\%) & P-value & Odds ratio \\
\hline \multirow[t]{2}{*}{ Sex } & Male & 1078 & 166 & 15.39 & \multirow[t]{2}{*}{$2.10^{-7}$} & \multirow[t]{2}{*}{2.10} \\
\hline & Female & 1026 & 82 & 7.99 & & \\
\hline \multirow{4}{*}{$\begin{array}{l}\text { Age group } \\
\text { (years) }\end{array}$} & $\leq 20$ & 375 & 9 & 2.4 & \multirow[t]{4}{*}{0.000} & \multirow[t]{4}{*}{0.12} \\
\hline & $21-40$ & 876 & 41 & 4.68 & & \\
\hline & $41-60$ & 588 & 168 & 28.85 & & \\
\hline & $\geq 60$ & 265 & 30 & 11.32 & & \\
\hline Body mass & Thinning & 76 & 4 & 5.26 & 0.000 & 0.04 \\
\hline
\end{tabular}




\begin{tabular}{|l|c|c|c|c|c|}
\hline \multirow{7}{*}{} & Normal & 1592 & 49 & 3.07 & \\
\cline { 2 - 5 } & Overweight & 311 & 137 & 44.01 \\
\cline { 2 - 5 } & Obesity 1 & 112 & 51 & 45.55 & \\
\cline { 2 - 6 } & Obesity 2 & 13 & 7 & 53.83 & \\
\cline { 2 - 6 } & Obesity 3 & 0 & 0 & 0 & \\
\hline
\end{tabular}

This table presents the percentages of diabetics according to the different factors: sex, age and BMI and P-value to indicate the significance or not of the diference observed. Considering that the difference is significant if $\mathrm{p}<0.05$.

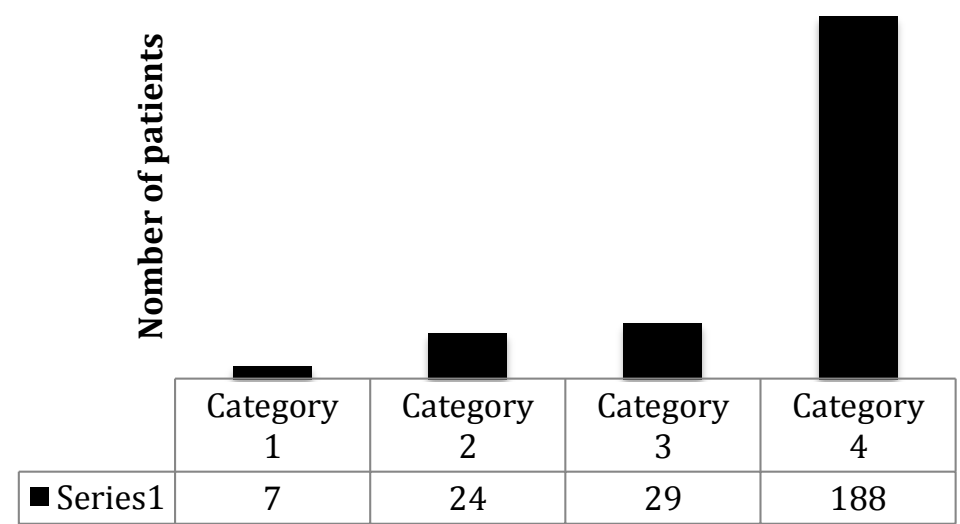

Figure 1:- Distribution of diabetic patients by socio-professional category

This figure presents the distribution of diabetics according to the different categories: Category 1: Represented wellto-do social classes, wealthy merchants, senior managers and businessmen; Category 2: Traders and owners of medium-sized enterprises, master's level managers; Category 3: Small businesses, small businesses, lower management; Category 4: Workers, farmers, women in households, unemployed.

\section{Discussion:-}

The prevalence of diabetes in Haut-Ogooué province is $11.78 \%$. This value is five times greater than that assessed by the National Program for the Control of Non-Communicable Diseases (PNLMNT) in 2013 in Kango, a small town in the Estuary province which was $2.90 \%$ [18]. However, this prevalence is close to that evaluated by IDF in Gabon in 2012 which was $10.19 \%$ [6].

Analysis of the distribution of patients according to sex and age firstly shows that the disease affects both men and women with a sex ratio of $2.02(166 / 82)$ and then an increase in the overall frequency Of diabetes to $28.85 \%$ the highest in the 41 to 60 age group, followed by a decrease for the oldest age group over 60 (Table 1). The analysis also shows a male morbidity of the disease, with $66.93 \%$ of men against $19.75 \%$ of women $\left(p=2.10^{-7}\right)$ in the most affected age group of 41 to 60 years. On the other hand, the study carried out in Kango by the National Program for the Control of Non-transmissible Diseases shows that women are more affected than men, with $63 \%$ compared to $37 \%$ [20]. However, another study conducted in Libreville from October 1990 to June 1994 also shows that men are the most affected by diabetes compared to women and the age group of 51 to 60 years was the most affected with $25.65 \%$, this rate drops to $7.01 \%$ after 70 years [7]. Many studies of African populations report a morbidity of the disease in men, especially in young patients in the 30-60 age group [2;17]. This can be explained by the fact that in African societies, risk factors for alcohol and tobacco use are higher among men [15].

Analysis of the body mass index (BMI) distribution shows that diabetes is often associated with overweight characterized by an increase in body mass index $\left(B M I>25 \mathrm{~kg} / \mathrm{m}^{2}\right)$, the elevation of the abdominal perimeter and all the elements characterizing the metabolic syndrome [2]. The study shows that $(44.1 \%)$ of diabetics are overweight and $(45.55 \%)$ are obese compared to normal people $(3.07 \%)$ (Figure 1). These data are close to those published in a recent study that shows a total BMI of $55 \%$ of overweight or obese diabetic patients, with women generally larger than men $\left(32.60 \%\right.$ vs $\left.29.40 \%, p=9.10^{-3}\right)$ [9]. In Senegal, a study by Sankale shows that obesity exists in 60 to $67 \%$ of cases in certain regions of Senegal and Côte d'Ivoire. With the phenomenon of urbanization in the African countries, there is a modification of the diets which associates with the basic model highly carbohydrate and generally composed of cereals or tubers, the development of "out-of-home" meals containing high proportions of carbohydrates and of lipids (bread and fries, for example). A study carried out in Douala showed that women and 
people aged 40 years and over were the most affected by diabetes with a higher risk for women than men [10]. In addition, the anatomy, physiology and metabolism of women predispose them to obesity, in addition to the fact that in Africa they often have a sedentary lifestyle, as in some studies have shown in Cameroon [11; 12], in Guinea Conakry [13] and in Cote d'Ivoire [14].

The study of socio-occupational factors shows that 188 out of 248 diabetics belong to category 4, ie 75.80\%. Thus, the most vulnerable people living with the disease are workers, farmers, women in the household, and the unemployed $\left(\mathrm{p}=1.92 .10^{-7}\right.$; odds ratio $=2.4$ ) (Figure 2$)$. A study carried out in Benin, Cotonou, also confirmed that diabetes affects mostly the less affluent, with $64.44 \%$ of the patients and in DRC Congo $92 \%$ of the subjects belonging to the low and middle socioeconomic groups [15].

The nutritional transition generated by urban migration has reinforced the role of precariousness as a contributing factor to the development of diabetes and obesity. In fact, the most precarious subjects will have more abundant food in the city but will choose cheap foodstuffs with high caloric content. The second aspect is the impossibility for many to ensure the cost of drugs especially insulin [16].

Finally, a third aspect is due to the impossibility of following an adapted diet, the low resources lead to preferential high caloric nutrients rich in fats, sugars and salt [17]. The study also shows that alcoholism and hypertension are risk factors associated with diabetes with $8.06 \%$ of alcoholic patients and $14.51 \%$ of hypertensive patients. This value is low compared to that found in a study carried out in Libreville from 1991 to 1993 [7] which shows a frequency three times higher $(40 \%)$ of the association of diabetes and HTA compared to that found in the HauteOgooue.

\title{
Conclusion:-
}

In the end, the study shows that diabetes is pathology strongly established among the Gabonese population, with an increasing evolution over the years and the prevalence obtained shows that Gabon is one of the countries most affected by this pathology. Men are the most exposed to the disease compared to women. On the distribution of body mass index (BMI), people at risk are those who are in overweight and obese. On the other hand, people who are economically weak or in precarious conditions are the most vulnerable to diabetes without access to health care facilities and expensive medicines, and changes in diet can explain this situation. There is a national program for the control of non-communicable diseases in Gabon, but its effectiveness has not yet been demonstrated in the face of the seriousness of this disease. Similarly, poverty reduction strategies in Gabon, where 30\% of the population live below the poverty line (official source), will have to be multiplied in order to reduce the impact of this disease in this segment of the population and in the area rural development. The fact that the prevalence evolves each year instead of decreasing becomes a significant problem of public health on which the Gabonese authorities should face with a more effective assumption of responsibility of the patients. The alternative methods of treatment are to be sought in particular with the use of the medicinal plants which could bring solutions using new natural substances and inexpensive for the patients.

\author{
Abreviations:- \\ High Density Lipoprotein (HDL); Low Density Lipoprotein (LDL); Triglycerides (TG) and Low Cholesterol \\ (HDL).
}

\section{Acknowledgements:-}

The authors thank the Africa University of the Francophonie (AUF) for funding this research project. They also thank Doctors Mboui Ondo Statiana and Kassa Kassa Fabrice of the CIRMF.

\section{Conflict of Interest:-}

The authors declare that there are no competing interests. All the authors read and approved the final version. 


\section{References:-}

1. Béran D, Besançon, Bowis J. Le diabete, un probleme majeur de santé publique pour l'Afrique. Revue ReMeD 2006; ${ }^{\circ} 33$.

2. Gning SB, Thiam M, Fall F, Ba-Fall K, Mbaye PS, Fourcade L. Le diabète sucré en Afrique subsaharienne aspects épidémiologiques, difficultés de prise en charge. Medecine Tropicale 2007; 67: 607-611.

3. Brown JB, Ramaiya K, Besançon S, Rheeder P, Tassou CM, Mbanya JC et al. Use of Medical Services and Medicines Attributable to Diabetes in Sub-Saharan Africa. PLoS One 2014; 9 (9): e106716.

4. International Diabetes Federation. Diabetes Atlas of the IDF, $5^{\text {th }}$ Edition 2011. http://www.idf.org/ diabetesatlas

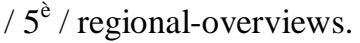

5. International Diabetes Federation IDF. Diabetes Atlas, $6^{\text {th }}$ edition, $2013.160 \mathrm{p}$.

6. Ondo NG. Le Gabon, point de départ de la campagne de DENA contre le diabète 2013 http://gabonreview.com/blog/le-gabon-point-de-depart-de-la-campagne-de-dena-contre-le-diabete/.

7. Ntyonga-Pono MP. L'hypertension artérielle chez le diabétique gabonais. Médecine d'Afrique Noire 1996; 43 (7) : 434-437.

8. American Diabetes Association Diabetes Care. Diagnosis and classification of diabetes mellitus. Diabetes Journals.org $2012 ; 35$ (1) : 64-71.

9. Ovono AF, Bekale S, Fernandez J, Mbang BA and Ngou-Milama E. Cardiovascular risk factors in type 2 diabetic patients in Libreville, Gabon. African Journal of Diabetes Medicine 2001; 19 (2):1.

10. Bita FAA, Lemogoum D, Owona MJ, Dissongo JII, Tobbit R, Ngounou-Moyo DF et al. Epidémiologie de l'obésité en milieu du travail à Douala, Cameroun. Revue Médicale de Bruxelles $2012 ; 33$ : 131-7.

11. Fezeu L, Minkoulou E, Balkau B, Kengne AP, Awah P, Unwin N et al. Association Between socioeconomic status and adiposity in urban Cameroon, International Journal of Epidemiology 2006; 35: 105-111.

12. Sobngwi E, Mbanya JCN, Unwin NC, Kengne AP, Fezeu L, Minkoulou EM et al. Physical activity and its relationship with obesity, hypertension and diabetes in urban and rural Cameroon. International journal of obesity and related metabolic disorders 2002; 26: 1009-10016.

13. Baldé AM, Traoré S, Touré M, Diallo D, Keita A, Magassouba FB et al. Hypertension artérielle en Guinée: Epidémiologie et place de la phytothérapie dans la prise en charge en zones urbaines et rurales de Fria, Boke, Forecariah (Basse Guinée). Pharmacopée et médecine traditionnelle africaine 2006; 12: 19-43.

14. Koffi NM, Sally SJ, Kouame P, Silue K, Diarra-Nama AJ. Faciès de l'hypertension artérielle en milieu professionnel à Abidjan. Médecine d'Afrique Noire $2001 ; 48: 257-60$.

15. Monteiro B, Gninafon M, Amoussou KJ. Contribution à l'étude épidémiologique du diabète sucre de l'adulte au centre national hospitalier et universitaire de Cotonou (C.N.H.U), Bénin. Medecine d'Afrique Noire 1991; 38 (4): 263-269.

16. Elrayah H, Eltom M, Beoriet A. Economic burden in families of childhood type 1 diabetes in urban Sudan. Diabetes Research and Clinical Practice 2005; $70: 159-65$.

17. Jaffiol C. Communication : Le Diabète sucré en Afrique. Bulletin Académie nationale de médecine 2011; 195 (6) : 1239-1254.

18. Ecke-Nzengue JE. Rapport d'activité de la journée mondiale du diabète, faisons un pas pour le diabète, 2013; $43 \mathrm{p}$. 